\title{
Complementary and Alternative Medicine Use and Its Association with Emotional Status and Quality of Life in Patients with a Solid Tumor: A Cross-Sectional Study
}

\author{
Aelee Jang, PhD, RN, Duck-Hee Kang, PhD, RN, ${ }^{1, \dagger}$ and Dong Uk Kim, PhD, $\mathrm{MD}^{2}$
}

\begin{abstract}
Objectives: Complementary and alternative medicine (CAM) has been used widely in various populations for various purposes, including emotional support and improvement of quality of life (QOL). However, CAM use and purposes for using CAM are less clear among Korean patients with a solid tumor. The purpose of this study was to determine the prevalence and type of CAM use, and the association between CAM use and anxiety, depression, and QOL in patients with a solid tumor.

Design: A cross-sectional survey.

Setting: A cancer center in Korea.

Subjects: Two hundred and sixteen patients diagnosed with a solid tumor.

Outcome measures: Standard questionnaires on CAM use, Hospital Anxiety and Depression Scale, and European Organization for Research and Treatment of Cancer QLQ-C30.

Results: One hundred thirty one patients (60.6\%) reported using CAM. CAM users, compared with nonCAM users, were significantly younger (57.8 vs. 60.9 years, $p=0.05)$, had higher level of education $(p=0.008)$, had higher income $(p=0.008)$, were less likely to seek physician consultation on CAM use $(p=0.002)$, and had a more advanced stage of tumor $(p=0.003)$ with more distant metastasis $(p=0.001)$. The most commonly used CAM was herbal medicine $(n=89,67.9 \%)$. CAM users had significantly lower anxiety $(t=5.21, p<0.001)$ and depression $(t=4.90, p<0.001)$ than non-CAM users. When the effects of CAM use were tested on anxiety, depression, and QOL, controlling for covariates, CAM use was significantly associated with $8.7 \%$ and $8.8 \%$ of variance in decreasing anxiety and depression, but there was no unique association of CAM use with variance in QOL.

Conclusions: CAM use is prevalent and younger age, higher education levels, higher income, less physician consultation, and higher cancer stage are significant correlates to CAM use. Controlling for covariates (e.g., gender, BMI), CAM use is significantly associated with lower anxiety and depression compared with those of non-CAM users.
\end{abstract}

Keywords: complementary and alternative medicine, cancer, herbal medicine, anxiety, depression, quality of life

\footnotetext{
${ }^{1}$ School of Nursing, The University of Texas Health Science Center at Houston, Houston, TX.

${ }^{2}$ School of Medicine, Pusan National University, and Biomedical Research Institute, Pusan National University Hospital, Busan, South Korea.

( ) Aelee Jang et al. 2017; Published by Mary Ann Liebert, Inc. This article is available under the Creative Commons License CC-BY-NC http://creativecommons.org/licenses/by-nc/4.0. This license permits non-commercial use, distribution and reproduction in any medium, provided the original work is properly cited. Permission only needs to be obtained for commercial use and can be done via RightsLink.

${ }^{\dagger}$ Deceased.
} 


\section{Introduction}

C ANCER PATIENTS FACE significant physiological, psychological, and socioeconomic challenges. Emotional distress, such as anxiety and depression, are common during cancer diagnosis and treatment, which can negatively affect quality of life (QOL). ${ }^{1-4}$ Although overall survival rates of cancer patients are continuously improving with advances in cancer treatments, ${ }^{5-7}$ how cancer patients manage their emotional distress and sustain QOL is less clear.

Complementary and alternative medicine (CAM) is commonly used in general and sick populations for various reasons and purposes. ${ }^{7-13}$ The National Center for Complementary and Integrative Health $(\mathrm{NCCIH})$ defines CAM as a group of diverse medical and healthcare systems, practices, and products that are not generally considered part of conventional medicine. ${ }^{14}$ Among several different categories of CAM, nonbiologically based therapies include acupuncture, hydrotherapy, massage, and music therapy, whereas biologically based therapies include herbal medicine, vitamins, and dietary supplements.

In cancer populations, up to $79 \%$ of cancer patients are known to use CAM. ${ }^{7,15-21}$ However, prevalence and type of CAM use in cancer patients may differ among different cultures and regions. For example, overall CAM use in European studies has been relatively lower than CAM use in Asian studies. ${ }^{17,18,20,21}$ Similarly, the use of herbal medicine has been high among Asian cancer patients, ${ }^{22-24}$ whereas western cancer patients primarily have used nonherbal medicine, such as vitamins and minerals. ${ }^{25-28}$ High use of herbal medicine among Asians typically is based on a belief that traditional Chinese medicine helps to improve cancer prognosis. ${ }^{17}$ In addition, sociodemographic factors, such as age, sex, education level, and income, in addition to clinical factors of tumor stage, disease duration, and family history of tumor, may affect the type and prevalence of CAM use. 7,16,29,30

Reasons and purposes for using CAM include longer survival, prevention of cancer recurrence, and improvement of immune function. ${ }^{31}$ Other reasons include alleviation of side-effects from conventional treatment, meeting unmet physical needs, managing emotional distress, and improving QOL. ${ }^{7,18,19,32,33}$ However, the actual efficacy of CAM use in meeting such purposes has not been adequately assessed. Similarly, data on the association between CAM use and emotional distress and QOL are limited. Therefore, the purposes of this study were to assess the prevalence and types of CAM use, and the association between CAM use and anxiety, depression, and QOL in Korean adult patients with a solid tumor.

\section{Materials and Methods}

Design

This was a cross-sectional study with one-time data collection.

\section{Participants}

Two hundred sixteen patients participated in the study. Inclusion criteria of the participants were as follows: (1) age 18 years or older, (2) confirmed diagnosis of having a solid tumor (3) no known psychiatric illness (e.g., schizophrenia), (4) no evidence of cognitive impairment, and (5) ability to speak and understand Korean. The types of solid tumors included were breast, lung, genitourinary, gynecologic, gastrointestinal, and head and neck cancer, but patients with nonmetastatic papillary thyroid cancer or endoscopically resected early gastric or colon cancer were excluded because patients with these tumors have a relatively high QOL compared to patients with other solid tumors due to minimal major organ dysfunction and a survival rate of nearly $100 \%$ with treatments. ${ }^{34}$ Patients were recruited from outpatient clinics during their clinic visits for postoperative follow-up, cancer treatment (chemotherapy and/or radiotherapy), or postcancer treatment checkup. Of 233 patients approached, $216(92.7 \%)$ consented to participate in the study. The sample size was estimated based on a low correlation coefficient between CAM use and anxiety (primary interest), $r=0.20$, power of $80 \%$, and significance level of alpha set at 0.05 . The study protocol was approved by the Institutional Review Board of the university-affiliated hospital in South Korea. All patients provided a written informed consent to participate in the study before data collection.

Data were collected using standardized questionnaires in a quiet consultation room in the clinic, and questionnaires were read to the participant for responses in a face-to-face interview. At the completion of data collection, participants received a small gift package for their time.

\section{Instrument}

Anxiety and depression were measured using the Hospital Anxiety and Depression Scale (HADS). HADS contains 14 items that are to be rated on a Likert scale of 0 to $3,0=$ not at all to $3=$ definitely/most of the time. ${ }^{35}$ HADS has two subscales of anxiety and depression, each including seven items with a potential range of score from 0 to 21 . Higher scores indicate higher levels of anxiety and depression. Cronbach's $\alpha$ in this study were 0.89 and 0.87 for anxiety and depression.

QOL was evaluated using the Korean version of European Organization for Research and Treatment of Cancer (EORTC) QLQ-C30, version 3, which is approved by the EORTC Data Center. The questionnaire includes both multiitem scales and single-item measures. The 30-item questionnaire is designed to assess global health status, five functional statuses (physical, role, emotional, cognitive, and social function), and nine symptoms (fatigue, nausea and vomiting, pain, dyspnea, loss of appetite, constipation, diarrhea, and financial difficulties). ${ }^{36}$ The global health status is calculated from two items on overall health last week and overall HRQoL last week on a 7-point scale $(1=$ very poor to 7 =excellent). The other 28 items for functional and symptom status are rated on a 4-point scale $(1=$ not at all to $4=$ very much). All scale scores were linearly transformed from 0 to 100 according to the instrument instructions. High scores of global health and functional status represent high levels of health and function, whereas high scores of symptom scales indicate high degrees of symptoms. Cronbach's $\alpha$ for the EORTC QLQ-C30 was 0.91 in this study.

CAM Use was assessed using a 53-item questionnaire. Because the previous 38-item CAM questionnaire ${ }^{37}$ was short of assessing common CAM used by many patients, 15 items were added to include biologically based therapies (e.g., mineral supplements, antioxidant supplements) suggested by the Korean Ministry of Food and Drug Safety 
(MFDS). The revised 53-item questionnaire included both nonbiologically based therapies (e.g., acupuncture, homeopathy, prayer, massage) and biologically based therapies (e.g., herbal medicine, vitamins supplements). To each item, participants responded by answering yes or no for use of the item, and one open question was used to gain any additional CAM that was not included in the questionnaire.

Demographic and clinical information was collected from a background questionnaire. Items included age, body mass index (BMI), residency, marital status, religion, educational level, and monthly household income, comorbidity, physician consultation on CAM use, and satisfaction with conventional treatment. Information regarding cancer (e.g., cancer type and stage, time duration since cancer diagnosis, distant metastasis, and treatment information) was obtained from the medical records.

\section{Data analysis}

Descriptive statistics were calculated to describe the characteristics of participants and the prevalence and types of CAM used. Group differences between CAM users and non-CAM users were tested using chi-squared test for categorical data and independent $t$ test for continuous data. Spearman's rho and Pearson correlation coefficients were used to assess the association between demographic and clinical information and anxiety, depression, and QOL. Hierarchical multiple linear regression analysis was used to test the association between CAM use and anxiety, depression, and QOL. In step 1 of the hierarchical linear regression analyses, significant covariates (gender, BMI, time duration since cancer diagnosis, and cancer treatment for anxiety; gender and time duration since cancer diagnosis for depression; and time duration since cancer diagnosis for QOL) were entered, followed by entering the use of CAM in step 2. Standardized estimate $(\beta), \mathrm{F}$, Total $\mathrm{R}^{2}$, Adjusted $\mathrm{R}^{2}$, and $R^{2}$-change $\left(\Delta R^{2}\right)$ for each step were provided in the regression models. To check the multicollinearity concern, the variance inflation factor was estimated and found to be less than 10, indicating no concern with multicollinearity among independent variables. All statistical analyses were performed using SPSS 22.0 version (SPSS, Inc., Armonk, $\mathrm{NY}$ ) and $p<0.05$ were considered significant.

\section{Results}

\section{Characteristics of participants and differences between CAM users and non-CAM users}

The mean age of all participants $(N=216)$ was $59.0 \pm 11.6$ years and the mean BMI was $22.3 \pm 2.9 \mathrm{~kg} / \mathrm{m}^{2}$. Females comprised $69.4 \%$ of the participants, and nearly $40 \%$ of the participants had less than a high school education. The majority (85.7\%) were married, and $64.4 \%$ did not seek physician consultation on CAM use. CAM users were significantly younger (57.8 vs. 60.9 years old, $p=0.05)$, had higher level of education ( $p=0.008)$, had monthly higher income $(p=0.008)$, and less likely to seek physician consultation on CAM use than non-CAM users $(p=0.002)$ (Table 1).

For clinical characteristics, common cancer types included gynecologic $(31.0 \%)$, gastrointestinal $(24.1 \%)$, and breast cancer $(16.7 \%)$, and the majority of the patients $(70.4 \%)$ had been diagnosed with cancer more than 12 months prior. Chemotherapy was the most frequent type of cancer treatment $(41.2 \%)$ and $28.2 \%$ of patients had completed active cancer

Table 1. The Demographic Characteristics of Participants $(N=216)$

\begin{tabular}{|c|c|c|c|c|c|c|}
\hline Characteristics & Categories & $\begin{array}{c}\text { Total } \\
(\mathrm{N}=216)\end{array}$ & $\begin{array}{c}\text { CAM user } \\
(\mathrm{n}=131)\end{array}$ & $\begin{array}{c}\text { CAM nonuser } \\
(\mathrm{n}=85)\end{array}$ & $\chi^{2} / t$ & $\mathrm{p}$ \\
\hline & & $M e a n \pm S D$ & Mean $\pm S D$ & $M e a n \pm S D$ & & \\
\hline \multirow{3}{*}{$\begin{array}{l}\text { Age (years) } \\
\text { BMI }\left(\mathrm{kg} / \mathrm{m}^{2}\right)\end{array}$} & & $59.0 \pm 11.6$ & $57.8 \pm 11.3$ & $60.9 \pm 11.8$ & 1.99 & 0.05 \\
\hline & & $22.3 \pm 2.9$ & $22.3 \pm 2.6$ & $22.4 \pm 3.4$ & -0.12 & 0.90 \\
\hline & & $\mathrm{N}(\%)$ & $\mathrm{N}(\%)$ & $\mathrm{N}(\%)$ & & \\
\hline Gender & $\begin{array}{l}\text { Male } \\
\text { Female }\end{array}$ & $\begin{array}{r}66(30.6) \\
150(69.4)\end{array}$ & $\begin{array}{l}38(29.0) \\
93(71.0)\end{array}$ & $\begin{array}{l}28(32.9) \\
57(67.1)\end{array}$ & 0.38 & 0.54 \\
\hline Age $(\text { years })^{\mathrm{a}}$ & $\begin{array}{l}<65 \\
\geq 65\end{array}$ & $\begin{array}{r}151(69.9) \\
65(30.1)\end{array}$ & $\begin{array}{r}102(77.9) \\
29(22.1)\end{array}$ & $\begin{array}{l}49(57.6) \\
36(42.4)\end{array}$ & 10.01 & 0.002 \\
\hline Education level & $\begin{array}{l}\text { Elementary school } \\
\text { Middle school } \\
\text { High school } \\
\text { College/University }\end{array}$ & $\begin{array}{l}50(23.1) \\
36(16.7) \\
94(43.5) \\
36(16.7)\end{array}$ & $\begin{array}{l}23(17.6) \\
18(13.7) \\
62(47.3) \\
28(21.4)\end{array}$ & $\begin{aligned} 27 & (31.8) \\
18 & (21.2) \\
32 & (37.6) \\
8 & (9.4)\end{aligned}$ & 11.74 & 0.008 \\
\hline Marital status & $\begin{array}{l}\text { Single } \\
\text { Married } \\
\text { Missing }\end{array}$ & $\begin{aligned} 7 & (3.2) \\
185 & (85.7) \\
24 & (11.1)\end{aligned}$ & $\begin{aligned} 3 & (2.3) \\
115 & (87.8) \\
13 & (9.9)\end{aligned}$ & $\begin{array}{c}4(4.7) \\
70(82.4) \\
11(12.9)\end{array}$ & 1.53 & 0.47 \\
\hline Income/mo $(\$)^{\mathrm{b}}$ & $\begin{array}{l}<3,000 \\
\geq 3,000\end{array}$ & $\begin{array}{r}142(65.7) \\
74(34.3)\end{array}$ & $\begin{array}{l}77(58.8) \\
54(41.2)\end{array}$ & $\begin{array}{l}65(76.5) \\
20(23.5)\end{array}$ & 7.16 & 0.008 \\
\hline Physician consultation & $\begin{array}{l}\text { Yes } \\
\text { No }\end{array}$ & $\begin{array}{r}77(35.6) \\
139(64.4)\end{array}$ & $\begin{array}{l}36(27.5) \\
95(72.5)\end{array}$ & $\begin{array}{l}41(48.2) \\
44(51.8)\end{array}$ & 9.68 & 0.002 \\
\hline
\end{tabular}

Italic bold values are significant.

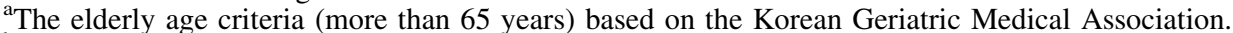

${ }^{\mathrm{b}}$ The average monthly wage of workers was \$3000 in 2015 in Korea (Ministry of Employment \& Labor in Korea).

BMI, body mass index; CAM, complementary and alternative medicine; SD, standard deviation. 
Table 2. The Clinical Characteristics of Participants $(N=216)$

\begin{tabular}{|c|c|c|c|c|c|c|}
\hline Characteristics & Categories & $\begin{array}{c}\text { Total } \\
(\mathrm{N}=216)\end{array}$ & $\begin{array}{l}\text { CAM user } \\
(\mathrm{n}=131)\end{array}$ & $\begin{array}{l}\text { CAM nonuser } \\
(\mathrm{n}=85)\end{array}$ & $\chi^{2} / t$ & $\mathrm{p}$ \\
\hline Cancer type & $\begin{array}{l}\text { Head and neck } \\
\text { Lung } \\
\text { Breast } \\
\text { Gastrointestinal } \\
\text { Genitourinary } \\
\text { Gynecologic } \\
\text { Others }\end{array}$ & $\begin{array}{c}26(12.0) \\
20(9.3) \\
36(16.7) \\
52(24.1) \\
12(5.6) \\
67(31.0) \\
3(1.3)\end{array}$ & $\begin{aligned} 14 & (10.7) \\
9 & (6.9) \\
24 & (18.3) \\
31 & (23.7) \\
8 & (6.1) \\
43 & (32.8) \\
2 & (1.5)\end{aligned}$ & $\begin{aligned} 12 & (14.1) \\
11 & (12.9) \\
12 & (14.1) \\
21 & (24.7) \\
4 & (4.8) \\
24 & (28.2) \\
1 & (1.2)\end{aligned}$ & 3.70 & 0.72 \\
\hline $\begin{array}{l}\text { Time duration } \\
\text { since diagnosis/mo }\end{array}$ & $\begin{array}{l}<6 \\
6-12 \\
>12\end{array}$ & $\begin{array}{r}34(15.7) \\
30(13.9) \\
152(70.4)\end{array}$ & $\begin{array}{l}16(12.2) \\
20(15.3) \\
95(72.5)\end{array}$ & $\begin{array}{l}18(21.1) \\
10(11.8) \\
57(67.6)\end{array}$ & 3.31 & 0.19 \\
\hline Cancer stage & $\begin{array}{l}\text { T1 } \\
\text { T2 } \\
\text { T3 } \\
\text { T4 }\end{array}$ & $\begin{array}{l}63(29.2) \\
26(12.0) \\
57(26.4) \\
70(32.4)\end{array}$ & $\begin{array}{ll}37 & (28.3) \\
11 & (8.4) \\
29 & (22.1) \\
54 & (41.2)\end{array}$ & $\begin{array}{l}26(30.6) \\
15(17.6) \\
28(33.0) \\
16(18.8)\end{array}$ & 14.02 & 0.003 \\
\hline $\begin{array}{l}\text { Distant } \\
\text { metastasis } \\
\text { Treatment }\end{array}$ & $\begin{array}{l}\text { M0 } \\
\text { M1 } \\
\text { Surgery } \\
\text { Chemotherapy } \\
\text { Radiotherapy } \\
\text { CRRT } \\
\text { Post-treatment }\end{array}$ & $\begin{aligned} & 148(68.5) \\
& 68(31.5) \\
& 51(23.6) \\
& 89(41.2) \\
& 4(1.9) \\
& 11(5.1) \\
& 61(28.2)\end{aligned}$ & $\begin{array}{c}79(60.3) \\
52(39.7) \\
27(20.6) \\
50(38.2) \\
2(1.5) \\
8(6.1) \\
44(33.6)\end{array}$ & $\begin{array}{c}69(81.2) \\
16(18.8) \\
24(28.2) \\
39(45.9) \\
2(2.4) \\
3(3.5) \\
17(20.0)\end{array}$ & $\begin{array}{r}10.41 \\
6.28\end{array}$ & $\begin{array}{l}\mathbf{0 . 0 0 1} \\
0.18\end{array}$ \\
\hline
\end{tabular}

Italic bold values are significant.

Unless otherwise noted, values are the number (percentage) of patients.

${ }^{\text {a}}$ Postoperative follow-up.

${ }^{b}$ Postcancer treatment checkup.

CRRT, concurrent chemoradiotherapy.

treatment. CAM users had a significantly advanced stage of tumor $(p=0.003)$ with more distant metastasis $(p=0.001)$ than non-CAM users, but there were no differences in cancer types, time duration since cancer diagnosis, and types of cancer treatment between CAM users and non-CAM users (Table 2).

\section{Prevalence and types of CAM use}

Of 216 patients, 131 patients $(60.6 \%)$ used at least one CAM (Table 3). On average, CAM users reported using $3.3 \pm 2.4$ different types of CAM. For specific categories of CAM, 23 patients (17.5\%) used nonbiologically based therapies only, 36 patients (27.5\%) biologically based therapies only, and 72 patients $(55.0 \%)$ used both categories of CAM. Acupuncture was the most commonly used nonbiologically based therapy $(n=49 ; 37.4 \%)$, whereas herbal medicine $(n=89 ; 67.9 \%)$ was the most commonly used biologically based therapy, followed by use of vitamins $(n=71 ; 54.2 \%)$, fatty acids $(n=26 ; 19.8 \%)$, and minerals $(n=24 ; 18.3 \%)$. Herbal medicine included dietary supplements approved by the MFDS $(n=62 ; 47.3 \%)$, such as red ginseng $(n=26 ; 19.8 \%)$ and mushroom $(n=24 ; 18.3 \%)$, and natural foods not approved by the MFDS ( $n=54 ; 41.2 \%$ ), such as firefly wormwood $(n=25 ; 19.1 \%)$ and black garlic juice $(n=13,9.9 \%)$ (Table 3$)$.

\section{Association between CAM use and anxiety, depression, and $Q O L$}

Because a large proportion of the participants were not using any CAM, the association of CAM use with anxiety, depression, and QOL was examined by comparing
Table 3. Frequencies of the Use for Specific Complementary and Alternative Medicine

\begin{tabular}{lc}
\hline Name (scientific name) & No. of users $(\%)$ \\
\hline Nonbiologically based therapies ${ }^{\mathrm{a}}$ & $95(72.5)$ \\
Acupuncture & $49(37.4)$ \\
Heat treatment & $18(13.7)$ \\
Prayer & $10(7.6)$ \\
Relax massage & $10(7.6)$ \\
Hydrotherapy & $8(6.1)$ \\
Mugwort moxibustion & $6(4.6)$ \\
Biologically based therapies ${ }^{\mathrm{a}}$ & $108(82.5)$ \\
Vitamins & $71(54.2)$ \\
Minerals & $24(18.3)$ \\
Fatty acids & $26(19.8)$ \\
Amino acids and proteins & $7(5.3)$ \\
Dietary fiber & $11(8.3)$ \\
Probiotics & $20(15.3)$ \\
Herbal medicine & $89(67.9)$ \\
Approved by MFDS & $62(47.3)$ \\
Red ginseng & $26(19.8)$ \\
Mushroom & $24(18.3)$ \\
Others & $22(16.8)$ \\
Not approved by MFDS & $54(41.2)$ \\
Mistletoe & $7(5.3)$ \\
Dandelion & $12(9.2)$ \\
Firefly wormwood & $25(19.1)$ \\
Green vegetable juice & $11(8.4)$ \\
Black garlic juice & $13(9.9)$ \\
Others & $32(24.4)$ \\
\hline
\end{tabular}

${ }^{\mathrm{a}}$ Multiple doses.

MFDS, Ministry of Food and Drug Safety. 
Table 4. Comparison of Anxiety, Depression, and Quality of Life Between Complementary and Alternative Medicine Users and Complementary and Alternative Medicine Nonusers ( $N=216$ )

\begin{tabular}{|c|c|c|c|c|c|c|}
\hline Characteristics & Categories & $\begin{array}{c}\text { Total } \\
(\mathrm{N}=216)\end{array}$ & $\begin{array}{c}\text { CAM user } \\
(\mathrm{n}=131)\end{array}$ & $\begin{array}{c}\text { CAM nonuser } \\
(\mathrm{n}=85)\end{array}$ & $\chi^{2} / t$ & $\mathrm{p}$ \\
\hline Anxiety & & $6.6 \pm 3.9$ & $5.6 \pm 3.4$ & $8.2 \pm 4.0$ & 5.21 & $<0.001$ \\
\hline Depression & & $7.4 \pm 4.2$ & $6.3 \pm 3.9$ & $9.0 \pm 4.2$ & 4.90 & $<0.001$ \\
\hline \multicolumn{7}{|l|}{ Quality of life } \\
\hline Global health status & Total & $52.7 \pm 23.7$ & $53.2 \pm 22.7$ & $51.8 \pm 25.4$ & 0.45 & 0.66 \\
\hline \multirow[t]{5}{*}{ Functioning } & Physical & $70.0 \pm 24.7$ & $72.3 \pm 22.3$ & $66.4 \pm 27.8$ & 1.63 & \\
\hline & Role & $71.2 \pm 30.5$ & $72.1 \pm 29.7$ & $69.8 \pm 31.8$ & 0.55 & \\
\hline & Emotional & $70.5 \pm 25.1$ & $72.8 \pm 23.8$ & $67.0 \pm 26.7$ & 1.69 & \\
\hline & Cognitive & $76.6 \pm 22.2$ & $78.5 \pm 22.3$ & $73.7 \pm 21.7$ & 1.55 & \\
\hline & Social & $69.8 \pm 29.2$ & $68.7 \pm 29.2$ & $71.6 \pm 29.3$ & -0.70 & \\
\hline \multirow[t]{9}{*}{ Symptoms } & Fatigue & $41.0 \pm 27.2$ & $40.4 \pm 26.6$ & $42.0 \pm 28.4$ & -0.42 & \\
\hline & Nausea/vomiting & $15.2 \pm 23.6$ & $15.0 \pm 23.7$ & $15.5 \pm 23.7$ & -0.15 & \\
\hline & Pain & $24.0 \pm 30.2$ & $22.8 \pm 29.3$ & $25.9 \pm 31.6$ & -0.74 & \\
\hline & Dyspnea & $20.2 \pm 28.7$ & $20.1 \pm 29.4$ & $20.4 \pm 27.7$ & -0.07 & \\
\hline & Insomnia & $29.9 \pm 31.5$ & $29.3 \pm 30.7$ & $31.0 \pm 32.9$ & -0.39 & \\
\hline & Loss of appetite & $28.7 \pm 32.5$ & $28.5 \pm 32.3$ & $29.0 \pm 32.9$ & -0.12 & \\
\hline & Constipation & $24.7 \pm 31.5$ & $20.4 \pm 27.9$ & $31.4 \pm 35.4$ & -2.42 & \\
\hline & Diarrhea & $17.3 \pm 25.9$ & $15.8 \pm 23.1$ & $19.6 \pm 29.7$ & -1.01 & \\
\hline & Financial difficulties & $31.0 \pm 29.3$ & $31.6 \pm 29.3$ & $30.2 \pm 29.4$ & 0.33 & \\
\hline
\end{tabular}

Italic bold values are significant.

Unless otherwise noted, values are mean \pm SD of patients.

CAM, complementary and alternative medicine.

differences between CAM users and non-CAM users on those variables. Compared with non-CAM users, CAM users had significantly lower levels of anxiety $(t=5.21$, $p<0.001)$ and depression $(t=4.90, p<0.001)$, but the two groups did not differ in QOL $(t=0.45, p=0.66)$ (Table 4$)$.

To determine how much variance in anxiety, depression, and QOL is explained by CAM use, we first controlled for the effects of covariates. Demographic and clinical factors showing significant Spearman's rho and Pearson correlation coefficients with anxiety, depression, and QOL were treated as covariates for each outcome. Significant covariates for anxiety were gender, BMI, time duration since cancer diagnosis, and cancer treatment type. For depression, significant covariates were gender and time duration since cancer diagnosis, and for QOL, only one significant covariate was time duration since cancer diagnosis. Hierarchical multiple linear regression analyses indicated that covariates accounted for $9.6 \%, 5.4 \%$, and $3.8 \%$ variances in anxiety, depression, and QOL. After controlling for covariates, use of CAM was un- iquely associated with $8.7 \%$ and $8.8 \%$ of variance in decreasing anxiety and depression, but there was no significant association of CAM use with variance in QOL (Table 5).

\section{Discussion}

The major findings of this study are that about $61 \%$ of Korean cancer patients are CAM users, and younger, more educated patients with higher incomes and advanced-stage cancer are more likely to use CAM with less consultation with a physician. Herbal medicine and acupuncture are among the most frequently used CAM followed by vitamins and fatty acids. When compared with non-CAM users, CAM users have significantly lower anxiety and depression but similar QOL.

The prevalence of CAM use in the literature has ranged from $23.6 \%$ to $79 \%$ among cancer patients. ${ }^{7,15-21}$ A large variability in the prevalence of CAM use may have been affected by factors such as different definitions of CAM,

Table 5. Predictors of AnXiety, Depression, and Quality of life

\begin{tabular}{|c|c|c|c|c|c|c|}
\hline \multirow[b]{2}{*}{ Predictor } & \multicolumn{2}{|c|}{ Anxiety } & \multicolumn{2}{|c|}{ Depression } & \multicolumn{2}{|c|}{$Q O L$} \\
\hline & $\triangle R^{2}$ & $\beta$ & $\triangle R^{2}$ & $\beta$ & $\triangle R^{2}$ & $\beta$ \\
\hline $\begin{array}{l}\text { Step } 1 \\
\text { Covariates }^{\mathrm{a}}\end{array}$ & $0.096 * * *$ & & $0.054 * *$ & & $0.038 * *$ & \\
\hline $\begin{array}{l}\text { Step } 2 \\
\text { Use of CAM }\end{array}$ & $0.087 * * *$ & $-0.299 * * *$ & $0.088 * * *$ & $-0.299 * * *$ & 0.000 & 0.012 \\
\hline $\begin{array}{l}\mathrm{F} \\
\text { Total } \mathrm{R}^{2} \\
\text { Adjusted } \mathrm{R}^{2}\end{array}$ & $\begin{array}{l}9.379^{* * *} \\
0.183 * * * \\
0.163\end{array}$ & & $\begin{array}{l}11.780 * * * \\
0.143 * * * \\
0.131\end{array}$ & & $\begin{array}{l}4.179^{*} \\
0.038 \\
0.029\end{array}$ & \\
\hline Adjusted $\mathrm{R}^{2}$ & 0.163 & & 0.131 & & 0.029 & \\
\hline
\end{tabular}

${ }^{\mathrm{a}}$ Covariates include gender, BMI, time duration since cancer diagnosis, and cancer treatment for anxiety; gender and time duration since cancer diagnosis for depression; and time duration since cancer diagnosis for QOL.

$* P<0.05, * * P<0.01, * * * P<0.001$.

QOL, quality of life. 
different sample characteristics, variable methods of survey, and geographical locations of the study. ${ }^{20,21,38}$ For example, in one study, CAM was defined as medical interventions not taught widely at U.S. medical schools or not generally available at U.S. hospitals, ${ }^{39}$ whereas in another study, CAM was defined as practices and products of nonmainstream origins. ${ }^{14}$ Because these definitions did not provide the specific types of CAM, responses may have varied by individual interpretation of CAM. Furthermore, CAM use appears to vary according to geographical location; in studies of similar cancer populations, the prevalence of CAM use was relatively lower in European countries (23.6-32\%) than in Asian countries (around 55\%). ${ }^{17,18,20,21}$ The prevalence of CAM use in cancer survivors appears to be higher than that in cancer patients who are receiving active treatment, up to $79 \%$ in American studies and $49.4 \%$ in European studies. ${ }^{15,32}$ Furthermore, the prevalence of CAM use can differ significantly by the mode of survey. In a German study of cancer patients, an internet survey indicated a CAM use rate of $77 \%$, but when an oncologist asked the patients, $74 \%$ of these patients denied using CAM. ${ }^{40}$ This large variability in the prevalence of CAM use has limited our understanding of the actual significance of CAM use. Therefore, we need to evaluate the prevalence of CAM use with precise definitions and proper survey tools for future planning and monitoring of CAM use in cancer patients.

The findings related to covariates of this study are mostly consistent with previous findings. CAM use has been higher in female gender, ${ }^{25,41}$ younger age, ${ }^{41,42}$ higher education level, ${ }^{18,41-43}$ higher income, ${ }^{25,41}$ palliative care setting, ${ }^{32}$ and positive family history of advanced cancer (stage IV and distant metastasis), ${ }^{18,42,43}$ although there was a nonsignificant association between CAM use and income. ${ }^{44}$ In addition, more information on CAM appears to promote more CAM use. ${ }^{45}$ Patients in this study indicated that only $36 \%$ consulted with their physicians. In another study, consultation with a medical practitioner on CAM was a little higher at $42 \% .{ }^{40}$ Most information on CAM use comes from families and friends $(49 \%)$ and the media $(39 \%)^{46}$ with limited consultation with an oncologist or physician who is directly involved in active conventional cancer treatment. This lack of communication may result in undesirable consequences via potential interactions between conventional cancer treatment and particular types of CAM. More open discussions between healthcare providers and patients are essential to promote the best care possible for patients. Furthermore, healthcare provider need to get a general training program about CAM for providing cancer patients with more reliable information and preventing undesirable consequences.

Similar to previous findings, ${ }^{20-22}$ the most common CAM used was herbal medicine (67.9\%), and the most common reason for using CAM was to increase the body's ability to fight cancer. In most Asian studies, ${ }^{2-24}$ the use of herbal medicine has been relatively high, compared with only $20 \%-25 \%$ of patients using herbal medicine in Western countries. ${ }^{25-28}$ Herbal medicine is used widely for various conditions among Asians and is thought to reduce distressful symptoms associated with cancer. Herbal medicine, however, may have unexpected side-effects such as increasing the risk of adverse bleeding, ${ }^{38,47,48}$ hepatotoxicity, ${ }^{48,49}$ neurotoxicity, ${ }^{48}$ unwanted stimulation of the immune system, ${ }^{48,49}$ thrombocytopenia ${ }^{48}$ or renal failure, ${ }^{48,49}$ which can be highly detrimental to patients. On the other hand, minerals and vitamins are more commonly used by Westerners than by Asians, and their sideeffects have been well established. ${ }^{15}$ Once the side-effects of herbal medicine are better established, herbal medicine may be used more frequently by Westerners. Therefore, we need to evaluate the side-effects of herbal medicine in cancer patients and figure out the mechanisms of herbal medicine with regard to improving cancer-related symptoms.

CAM users had significantly lower anxiety and depression compared to non-CAM users in our study. After controlling for covariates, we found that CAM use uniquely explained $8.7 \%$ and $8.8 \%$ of variances in anxiety and depression, respectively, suggesting the potential efficacy of CAM use on emotional status. Some previous studies reported nonsignificant associations between CAM use and anxiety and depression, ${ }^{28,44}$ whereas in other studies, CAM treatment was reported to improve anxiety and depression. ${ }^{50,51}$ Given the competing views among previous reports, ${ }^{10,23}$ the correlation between CAM use and emotional well-being remains unclear. CAM use may result in an improved emotional state. In other words, patients with more subtle anxiety and depression symptoms may be more likely to pursue CAM versus those with severe symptoms. Fundamentally, this is an important issue since cancer patients may be exposed to inefficient emotional cares of which the effects cannot be completely understood through empirical measures. With regard to the current understood relationship between CAM use and emotional status in cancer patients, there is a lack of standardization that leads to unresolved issues related to the type of cares being taken, which CAMs are deemed effective, and how these care strategies work in relieving anxiety and depression. Therefore, well-designed prospective randomized controlled trials are needed to determine the potential relationship between CAM use and emotional improvement.

CAM use had no significant impact on QOL in this study. Also, a majority of investigators reported no significant difference in QOL between CAM users and non-CAM users among cancer patients. ${ }^{7,18,52-54}$ Furthermore, previous investigators reported that cancer patients with poor QOL were more likely to use CAM. ${ }^{55}$ These reports raise an interesting question on causality and specific reasons for using CAM. For example, in a previous study with American breast cancer patients, nearly $90 \%$ of the patients reported using prayer as the most common CAM, and the reason for praying was largely to gain a feeling of control. ${ }^{10}$ Thus, the personal goals of CAM use are various, and the reason for using a particular type of CAM may be not for improving QOL. Further investigations on specific reasons for using CAM and the subsequent satisfaction and efficacy of achieving individual goals would be beneficial.

The limitations of this study include a potential sample selection bias because all participants were recruited from the outpatient clinic, excluding patients who were receiving high dose chemotherapy and certain types of cancer with extremely positive prognosis. Second, because of a crosssectional design, the effects of CAM use on anxiety, depression, and QOL cannot be confirmed. When evaluating the efficacy of CAM use for cancer-related symptoms such as anxiety and depression a placebo effect should be considered in both cohort studies and well-designed comparative studies. ${ }^{56}$ For example, if CAM use is shown to improve anxiety and depression in $50 \%$ of patients the benefits of a placebo treatment should be shown in less than $50 \%$ of patients. The 
placebo effect is not well understood but may have had a strong influence of the results of the current study. Third, the study population was limited to Korean adult cancer patients and the findings of this study cannot be generalized beyond Korean culture and environments. Lastly, this investigation did not include further details on individual reasons for using each particular CAM or biobehavioral mechanisms to explain a potential link between CAM use and outcomes. Despite these limitations, findings of this study contribute to greater understanding on CAM use and its potential efficacy of CAM use on emotional status in Korean cancer populations.

\section{Conclusion}

CAM use was prevalent $(61 \%)$ in Korean adult cancer patients. The most commonly used CAM was herbal medicine and acupuncture. CAM users had a significantly lower anxiety and depression than non-CAM users, and CAM use explained about a $9 \%$ reduction of anxiety and depression when controlling for covariates. Younger age, higher education levels, higher income, less physician consultation, and higher cancer stage were significant correlates to CAM use.

\section{Acknowledgment}

The author acknowledges receiving funding to conduct the study from Pusan National University Hospital Biomedical Research Institute Grant 2013-20.

\section{Author Disclosure Statement}

No competing financial interests exist.

\section{References}

1. Kang JI, Sung NY, Park SJ, et al. The epidemiology of psychiatric disorders among women with breast cancer in South Korea: Analysis of national registry data. Psychooncology 2014;23:35-39.

2. Hwang JH, Kim WY, Ahmed M, et al. The use of complementary and alternative medicine by Korean breast cancer women: Is it associated with severity of symptoms? Evid Based Complement Alternat Med 2015;2015:182475.

3. Brown LF, Kroenke K, Theobald DE, et al. The association of depression and anxiety with health-related quality of life in cancer patients with depression and/or pain. Psychooncology 2010;19:734-741.

4. Diaz-Frutos D, Baca-Garcia E, García-Foncillas J, LópezCastroman J. Predictors of psychological distress in advanced cancer patients under palliative treatments. Eur J Cancer Care 2016;25:608-615.

5. Zhang Z, Gu XL, Chen ML, Liu MH, et al. Use of palliative chemo- and radiotherapy at the end of life in patients with cancer: A retrospective cohort study. Am J Hosp Palliat Care 2016 [Epub ahead of print]; http://dx.doi.org/ $10.1177 / 1049909116653733$

6. Byers T, Wender RC, Jemal A, Baskies AM, et al. The American Cancer Society challenge goal to reduce US cancer mortality by $50 \%$ between 1990 and 2015: Results and reflections. CA Cancer J Clin 2016;66:359-369.

7. Naja F, Fadel RA, Alameddine M, et al. Complementary and alternative medicine use and its association with quality of life among Lebanese breast cancer patients: A cross-sectional study. BMC Complement Altern Med 2015; 22:15:444.
8. Clarke TC, Black LI, Stussman BJ, et al. Trends in the use of complementary health approaches among adults: United States, 2002-2012. Natl Health Stat Report 2015;10:1-16.

9. Stussman BJ, Black LI, Barnes PM, et al. Wellness-related use of common complementary health approaches among adults: United States, 2012. Natl Health Stat Report 2015; $4: 1-12$.

10. Kang DH, McArdle T, Suh Y. Changes in complementary and alternative medicine use across cancer treatment and relationship to stress, mood, and quality of life. J Altern Complement Med 2014;20:853-859.

11. Bar-Sela G, Danos S, Visel B, Mitnik I. Understanding the attitudes of patients with cancer toward complementary and alternative therapies. J Palliat Med 2016;19:496-502.

12. Weeks L, Balneaves LG, Paterson C, Verhoef M. Decisionmaking about complementary and alternative medicine by cancer patients: Integrative literature review. Open Med 2014;8:e54-e66.

13. Nahin RL, Byrd-Clark D, Stussman BJ, Kalyanaraman N. Disease severity is associated with the use of complementary medicine to treat or manage type- 2 diabetes: Data from the 2002 and 2007 National Health Interview Survey. BMC Complement Altern Med 2012;12:193.

14. National Center for Complementary and Integrative Health. Complementary, alternative, or integrative health: What's in a name? Online document at http://nccam.nih.gov/health integrative-health. Accessed June 10, 2016.

15. John GM, Hershman DL, Falci L, et al. Complementary and alternative medicine use among US cancer survivors. J Cancer Surviv 2016;10:850-864.

16. Navo MA, Phan J, Vaughan C, et al. An assessment of the utilization of complementary and alternative medication in women with gynecologic or breast malignancies. J Clin Oncol 2004;22:671-677.

17. Shih V, Chiang JY, Chan A. Complementary and alternative medicine (CAM) usage in Singaporean adult cancer patients. Ann Oncol 2009;20:752-757.

18. Kang E, Yang EJ, Kim SM, et al. Complementary and alternative medicine use and assessment of quality of life in Korean breast cancer patients: A descriptive study. Support Care Cancer 2012;20:461-473.

19. Choi JY, Chang YJ, Hong YS, et al. Complementary and alternative medicine use among cancer patients at the end of life: Korean national study. Asian Pac J Cancer Prev 2012;13:1419-1424.

20. Molassiotis A, Fernandez-Ortega P, Pud D, et al. Complementary and alternative medicine use in colorectal cancer patients in seven European countries. Complement Ther Med 2005;13:251-257.

21. Molassiotis A, Panteli V, Patiraki E, et al. Complementary and alternative medicine use in lung cancer patients in eight European countries. Complement Ther Clin Pract 2006; 12:34-39.

22. Kim SY, Kim KS, Park JH, et al. Factors associated with discontinuation of complementary and alternative medicine among Korean cancer patients. Asian Pac J Cancer Prev 2013;14:225-230.

23. Kalender ME, Buyukhatipoglu H, Balakan O, et al. Depression, anxiety and quality of life through the use of complementary and alternative medicine among breast cancer patients in Turkey. J Cancer Res Ther 2014;10:962-966.

24. Cui Y, Shu XO, Gao Y, et al. Use of complementary and alternative medicine by Chinese women with breast cancer. Breast Cancer Res Treat 2004;85:263-270. 
25. Paltiel O, Avitzour M, Peretz T, et al. Determinants of the use of complementary therapies by patients with cancer. $\mathrm{J}$ Clin Oncol 2001;19:2439-2448.

26. Boon H, Stewart M, Kennard MA, et al. Use of complementary/alternative medicine by breast cancer survivors in Ontario: Prevalence and perceptions. J Clin Oncol 2000; 18:2515-2521.

27. Damery S, Gratus C, Grieve R, et al. The use of herbal medicines by people with cancer: A cross-sectional survey. Br J Cancer 2011;104:927-933.

28. Barnes PM, Powell-Griner E, McFann K, Nahin RL. Complementary and alternative medicine use among adults: United States, 2002. Adv Data 2004:1-19.

29. Harris P, Finlay IG, Cook A, et al. Complementary and alternative medicine use by patients with cancer in Wales: A cross sectional survey. Complement Ther Med 2003; 11:249-253.

30. Garland SN, Valentine D, Desai K, et al. Complementary and alternative medicine use and benefit finding among cancer patients. J Altern Complement Med 2013;19:876-881.

31. Liu J, Chen P, Wang R, et al. Effect of Tai Chi on mononuclear cell functions in patients with non-small cell lung cancer. BMC Complement Altern Med 2015;15:3.

32. Nissen N, Lunde A, Pedersen CG, Johannessen H. The use of complementary and alternative medicine after the completion of hospital treatment for colorectal cancer: Findings from a questionnaire study in Denmark. BMC Complement Altern Med 2014;14:388.

33. Burg MA, Adorno G, Lopez ED, et al. Current unmet needs of cancer survivors: Analysis of open-ended responses to the American Cancer Society Study of Cancer Survivors II. Cancer 2015;121:623-630.

34. Higuchi N, Nakamura K, Ihara E, et al. Preserved gastric motility in patients with early gastric cancer after endoscopic submucosal dissection. J Gastroenterol Hepatol 2013;28:494-498.

35. Zigmond AS, Snaith RP. The hospital anxiety and depression scale. Acta Psychiatr Scand 1983;67:361-370.

36. Aaronson NK, Ahmedzai S, Bergman B, et al. The European Organization for Research and Treatment of Cancer QLQ-C30: A quality-of-life instrument for use in international clinical trials in oncology. J Natl Cancer Inst 1993; 85:365-376.

37. Kang HP, Lee H, Oh TG, et al. The use of health functional foods in gastrointestinal cancer patients. Clin Nutr Res 2013;2:19-25.

38. Andersen MR, Sweet E, Zhou M, Standish LJ. Complementary and alternative medicine use by breast cancer patients at time of surgery which increases the potential for excessive bleeding. Integr Cancer Ther 2015;14:119-124.

39. Eisenberg DM, Kessler RC, Foster C, et al. Unconventional medicine in the United States. Prevalence, costs, and patterns of use. N Engl J Med 1993;328:246-252.

40. Huebner J, Prott FJ, Micke O, et al.; PRIO (Working Group Prevention and Integrative Oncology-German Cancer Society). Online survey of cancer patients on complementary and alternative medicine. Oncol Res Treat 2014;37:304-308.

41. Malak AT, Karayurt O, Demir E, Yümer AS. Complementary and alternative medicine in cancer patients analysis of influencing factors in Turkey. Asian Pac J Cancer Prev 2009;10:1083-1087.

42. Hyodo I, Amano N, Eguchi K, et al. Nationwide survey on complementary and alternative medicine in cancer patients in Japan. J Clin Oncol 2005;23:2645-2654.
43. Klafke N, Eliott JA, Wittert GA, Olver IN. Prevalence and predictors of complementary and alternative medicine (CAM) use by men in Australian cancer outpatient services. Ann Oncol 2012;23:1571-1578.

44. Gan GG, Leong YG, Bee PC, Chin E. The AKH. Complementary and alternative medicine use in patients with hematological cancers in Malaysia. Support Care Cancer 2015;23:2399-2406.

45. Huebner J, Ebel M, Muenstedt K, et al. A lecture program on complementary and alternative medicine for cancer patients-Evaluation of the pilot phase. J Cancer Educ 2015;30:340-343.

46. Tautz E, Momm F, Hasenburg A, Guethlin C. Use of complementary and alternative medicine in breast cancer patients and their experiences: A cross-sectional study. Eur J Cancer 2012;48:3133-3139.

47. Ahn JH, Kim SB, Yun MR, et al. Alternative therapy and abnormal liver function during adjuvant chemotherapy in breast cancer patients. J Korean Med Sci 2004;19:397-400.

48. De Smet PA. Health risks of herbal remedies: An update. Clin Pharmacol Ther 2004;76:1-17.

49. Alsanad SM, Williamson EM, Howard RL. Cancer patients at risk of herb/food supplement-drug interactions: A systematic review. Phytother Res 2014;28:1749-1755.

50. Bar-Sela G, Danos S, Visel B, et al. The effect of complementary and alternative medicine on quality of life, depression, anxiety, and fatigue levels among cancer patients during active oncology treatment: Phase II study. Support Care Cancer 2015:23:1979-1985.

51. Piet J, Würtzen H, Zachariae R. The effect of mindfulness based therapy on symptoms of anxiety and depression in adult cancer patients and survivors: A systematic review and meta-analysis. J Consult Clin Psychol 2012;80:1007-1020.

52. Korkmaz M, Tavsanli NG, Ozcelik H. Use of complementary and alternative medicine and quality of life of cancer patients: Turkish samples. Holist Nurs Pract 2016; 30:88-95.

53. Can G, Erol O, Aydiner A, Topuz E. Quality of life and complementary and alternative medicine use among cancer patients in Turkey. Eur J Oncol Nurs 2009;13:287-294.

54. Naing A, Stephen SK, Frenkel M, et al. Prevalence of complementary medicine use in a phase 1 clinical trials program: The MD Anderson Cancer Center experience. Cancer 2011;117:5142-5150.

55. Hlubocky FJ, Ratain MJ, Wen M, Daugherty CK. Complementary and alternative medicine among advanced cancer patients enrolled on phase I trials: A study of prognosis, quality of life, and preferences for decision making. J Clin Oncol 2007;25:548-554.

56. Cuijpers P, Karyotaki E, Andersson G, et al. The effects of blinding on the outcomes of psychotherapy and pharmacotherapy for adult depression: A meta-analysis. Eur Psychiatry 2015;30:685-693.

Address correspondence to: Dong Uk Kim, PhD, MD Department of Internal Medicine Pusan National University Hospital 1-10 Ami-dong Seo-gu Busan 602-739 South Korea

E-mail: amlm374@yahoo.co.kr 